\title{
Short-Term Outcome of Balloon Angioplasty of Discrete Coarctation of Aorta
}

\begin{abstract}
Introduction: Balloon angioplasty has been proposed as an alternative way to surgery in primary treatment of aortic coarctation (Co A) for both children and infants.

Objective: The purpose of this study is to assess the immediate and intermediate term effectiveness and safety of balloon angioplasty in infants and children with native discrete membranous Co A.

Patients and methods: Forty consecutive patients with native discrete coarctation of the aorta were treated with balloon angioplasty. They were 8 infants and 32 children; with ages ranged from 2 months to 10 years and all weighted below $35 \mathrm{Kg}$. All patients were clinically evaluated immediately after and at 6 to 12 months and 18 to 24 months after the procedure. Follow up data were collected and Doppler echocardiography was done before intervention to confirm diagnosis and to plan management and post interventional to follow-up patients and estimate the outcome and complications.

Results: Immediate successful relief of native Co A was obtained in $92.5 \%$ of the population study, while $7.5 \%$ recorded immediate suboptimal results with pressure gradient above $20 \mathrm{mmHG}$. The peak systolic gradient across the coarcted segment was reduced significantly with $82.5 \%$ immediately after balloon angioplasty, $75 \%$ and $73.2 \%$ at the end of first and second follow up period respectively. Pressure gradient decreased significantly from $57 \pm 15.7 \mathrm{mmHg}$ before balloon angioplasty to $14.23 \pm 11.30 \mathrm{mmHg} 9$ to 12 months after, but it was increased slightly to reach $15.15 \pm 11.80 \mathrm{mmHg}$ at the end of the second year. The systolic ascending aortic pressure decreased significantly (19\%) and the systolic descending aortic pressure increased significantly (11.4\%) at the end of the study. Recoarctation occurred in $17.5 \%$ at the end of the 1st year and balloon angioplasty was repeated for all patients successfully. At the end of the 2 nd year restenosis was evidenced in $10 \%$ of the whole study population. Aneurysm formation at the site of coarcted segment occurred in (5\%).
\end{abstract}

Conclusion: Balloon angioplasty is an effective and safe alternative to surgery for treatment of Co A in infants older than 2 months and children 10 years of age or younger.

Keywords: Coarctation of the aorta; Balloon angioplasty
Research Article

Volume 9 Issue 5 - 2017

Reda Biomy ${ }^{*}$, Heba Mansour ${ }^{2}$, EL Said

Abdel Khaliek ${ }^{2}$, HalaEL Farghaly ${ }^{3}$ and

Shahira Mohamad ${ }^{3}$

${ }^{1}$ Cardiology Department, Khafr ELshiek Faculty of Medicine, Egypt

${ }^{2}$ Cardiology Department, Benha Faculty of Medicine, Egypt

${ }^{3}$ National Heart Institute, Egypt

*Corresponding author: Reda Biomy, Cardiology Department, Faculty of Medicine, Banha University, Borg Elesraa, Elgomhorya Street, Behind Elgomhorya Cinema, Kafr Elshiek, Egypt, Tel: 01114383333;

Email: profreda59@yahoo.com

Received: July 21, 2017 | Published: September 20, 2017

\section{Introduction}

Aortic Coarctation (CoA) is a congenital cardiac lesion consisting of a narrow aortic segment which constitutes 5 to $8 \%$ of all Congenital Heart Disease (CHD). The classic form of CoA is located in the descending thoracic aorta distal to the left subclavian artery origin, at nearly the level of the ductal structure. Significant systemic arterial hypertension and/or congestive heart failure are prompt indications of intervention. If hypertension (rather that heart failure) is the presenting problem, it is preferable to relieve the obstruction promptly rather that medical treatment of hypertension with antihypertensive medications. Surgical relief of the aortic obstruction and catheter interventional techniques (balloon angioplasty and stents) are available alternatives [1].

Aortic coarctation includes a variety of lesions with variable degrees of hypoplasia of the aortic arch. There is either so severe aortic arch narrowing that is almost indistinguishable from interrupted aortic arch and arch hypoplasia, or on the other end of the spectrum the coarctation is discrete with a localized shelflike lesion within the aortic arch lumen often with tapering of the arch as it courses towards the obstruction [2]. There is more controversy about the optimal management of this vascular anomaly whether to balloon dilatation or stenting the native coarctation or operate upon, which surgical technique to select and the ideal age at intervention and the role of balloons and the different types of stents and the bioabsorbable stents for native and recurrent Coarctation [3]. Despite the initial enthusiasm created by the effectiveness of balloon angioplasty in the treatment of aortic coarctation $[4,5]$, the use of this technique became declined because the reported incidence of early recoarctation [6,7] and in particular, the aneurysm formation in the site of angioplasty [8]. Despite these limitations, the use balloon angioplasty as the 
treatment of choice for localized coarctation have continued. The long-term follow-up studies of balloon angioplasty demonstrated favorable results which is comparable to results of surgery, as well as the absence of progression of the aneurysm in some cases $[9,10]$. In addition, the increasing incidence of aortic aneurysms in patients with coarctation treated surgically, has kept the debate open regarding the proper treatment of aortic coarctation after the neonatal period [11].

Although balloon angioplasty typically results in favorable acute results, it is associated with a higher rate of both recurrent obstruction and aortic wall injury than stent therapy. As a result, stent placement is usually preferred when patient size and coarctation anatomy are suitable [12]. However, the use of conventional stents is restricted in newborns and young children because of continuous vessel growth, the possibility of redilatation, and later surgical removal. Several groups of researchers have used those techniques in the treatment of aortic coarctation in both children and adults. However, there is still a considerable controversy among cardiologist and surgeons with regard to whether the native aortic coarctation should be balloon dilated, stented or surgically treated [12]. The objectives of this work are to share our experience, regarding both the results and the short and intermediate-term follow-up when using this technique; and to retrospectively compare our results with the previous results and complications of the balloon angioplasties done for coarctation of the aorta

\section{Subjects and Methods}

\section{Study population}

Our study included 40 consecutive patients ( 8 infants and 32 children) with native discrete coarctation of the aorta referred for balloon angioplasty during a 2-years period from March 2013 to July 2015 at the National Heart Institute, Egypt. There were 27 males and 13 females; ages ranged from 2 months to 10 years (mean age is $3.6 \pm 2.8$ ); and all weighted below $35 \mathrm{Kg}$ (mean weight is $16.2 \pm 7.7$ ). All parents or guardians of those children gave an informed consent and the study protocol was approved by the local ethic committee and all patients were followed for 18 to 24 months after balloon angioplasty.

A. Exclusion criteria includes: Previous aortic coarctation angioplasty or surgery, long aortic coarctation segment, severe aortic arch hypoplasia, associated abdominal aortic coarctation segment, associated complex cardiac anatomy and associated pathological extra cardiac syndromes.

\section{Methods}

Through history taking was done with special emphasis on history of hypertension (all patients were hypertensive for age), intermittent claudication, headache, chest pain, shortness of breath, and difficulty of feeding especially for infants and young children; special interest was directed for drug intake. Physical examination was done included Simultaneous palpation of the radial and femoral pulses and measurement of blood pressure in upper and lower limbs under basal conditions while the patient is recumbent and calm. Cardiac examination, conventional 12 leads ECG, chest x-ray were done. Doppler echocardiography were done for all patients. It was done as a pre-interventional investigation to confirm diagnosis and to plan management; then as a post interventional investigation to follow-up patients and estimate the outcome and detect any complications. Different views were made as long axis parasternal, short axis parasternal of the aortic, mitral valve and subvalvular mitral levels, apical four chambers views, subcostal and finally suprasternal views. M mode measurements in the parasternal long axis view were done for left ventricular end diastolic dimension (LEDD) and left ventricular end systolic dimensions (LVESD), septal wall thickness (SWT) and posterior wall thickness (PWT), Fractional shortening (FS) and ejection fraction (EF) were then calculated. Finally, in the suprasternal view; the aortic arch was delineated; the coarcted segment was determined by 2D and color Doppler, continuous wave Doppler study was done by alignment the cursor across coarcted segment to detect the peak systolic velocity and diastolic component. The ascending aorta, aortic arch and aortic isthmus were visualized using the suprasternal view. The transverse aortic arch diameter was measured at the base of the left common carotid and aortic Isthmus diameter was measured at the base of the left subclavian artery also the coarcted segment diameter measured [13].

\section{Cardiac catheterization}

The procedure was performed under general anesthesia and arterial access was established through the right or left femoral artery using Seldinger technique. A 4 to 6 Fr introducer was selected, depending on the patient's weight. Heparin was administered (100-150 IU/kg intravenously, with a maximum dose of $5000 \mathrm{IU}$ ), with activated clotted time monitored regularly and maintained at $>200$ s. Either pig-tail or multipurpose catheters were used, Generally, the pig-tail catheters were used for injections of dye and the multipurpose catheters were used for pressure measurement and for crossing the coarcted segment. Pull back peak to peak systolic pressures were measured in the aorta proximal to the coarcted segment and the descending aorta distal to the coarcted segment. Aortic arch injections were made using a non-ionic dye at a general dose not exceeding $4 \mathrm{ml} / \mathrm{kg}$ for total injections. The anatomy of the transverse arch and the coarctation was defined by aortogram performed in the transverse aortic arch to show the narrowest part of the lesion in two different views. Angiographic projections included lateral and a left anterior oblique improved delineation of the lesion if the isthmus overlaps the descending aorta. A pigtail catheter with multiple markers or an angiographic catheter with calibration marks was used for accurate measurement of the diameter and length of the coarctation, the diameters of the transverse arch between the brachio-cephalic and the left common carotid artery, isthmus just after the origin of the subclavian artery, aorta proximal and distal to the coarctation and the aorta at diaphragm level. The origins of the brachiocephalic, carotid, and subclavian arteries are noted and irregularities or aneurysms of the aortic wall are carefully excluded. Those measurements were related to the size of the catheter used to avoid magnification errors. A long stiff 0.035 -inch exchange guide wire was placed through the retrograde injection catheter, with the tip in a secure position, either the left subclavian artery if it arises some distance away from the coarctation or has a large diameter, then it is the best option for anchoring the guide wire. If not, other alternatives are the ascending aorta or the right subclavian artery, the latter 
allowed for a straight and secure position of the guide wire. The tip of the guide wire was always kept away from the coronary, carotid, or vertebral arteries. The arterial introducer sheath was replaced by a larger size, if necessary, to accept the balloon selected. It was preferable to use a slightly larger vascular sheath than a balloon catheter inserted directly over a wire, which avoid the risk of arterial damage. The diameter of the initial balloon chosen for the procedure was equal to or $1 \mathrm{~mm}$ smaller than the diameter of the aorta immediately distal to the origin of the subclavian artery, and not exceeding the diameter of the aorta at the diaphragm. The shortest possible balloons for the specific anatomy were selected, covering the entire length of the coarctation with small shoulders. The balloon is advanced to just cross the coarctation, it is then centered at the coarctation level and inflated using a pressuremonitored inflation device till 5 atmospheric pressures, or until the waist disappears. The inflation/deflation times were not more than $10 \mathrm{sec}$ Balloon inflation is then repeated two to four times. The balloon was kept away from the carotid and vertebral arteries to minimize the risk of trauma. Once the coarctation has been dilated, the balloon is removed and a multipurpose catheter attached to a valve or hemostatic adaptor, or a Multi-Track TM catheter, is used. Gradients are recorded while crossing the coarctation area, maintaining the guide wire in position. Final angiograms in two different image views are obtained to detect any immediate complications (e.g. newly developed aneurysm or dissection), then pressure measurements were then repeated. The guide wire had not been withdrawn across the dilation site until the procedure is complete. A pigtail catheter was only removed over a guide wire, avoiding potential contact of the free tip with an intimal tear, which could cause additional trauma to the arterial wall. If there is still angiographic narrowing at the coarctation site or a significant residual peak systolic gradient is seen, and the aortic wall shows no damage, a balloon 1 to $2 \mathrm{~mm}$ larger may be used, not exceeding $10-15 \%$ of the normal size of the adjacent aorta, and not exceeding the diameter of the aorta at the diaphragm. Balloon angioplasty was considered successful when the post dilatation pressure gradient was $<20 \mathrm{mmHg}$ and the coarctation diameter was increased without formation of a significant aneurysm on repeat angiography (An aneurysm was defined as a saccular outpouching protrusion of the aortic wall or fusiform dilatation with a ratio of its diameter to the descending aorta diameter more than 1.5 at follow-up) [14].

Follow-up: All patients underwent periodic clinical evaluation immediately after and at 6 to 12 months and 18 to 24 months. Follow-up data were collected consisting mainly of history taking, cardiovascular examination with special emphasis to measurement of upper and lower limb blood pressure; blood pressure was measured in the right arm and in the leg contralateral to the side used for angioplasty. Doppler echocardiography was done to demonstrate the specific changes in the site of obstruction, to determine the cardiac functions and to detect any complications (specially recoarctation and aneurysm). While pulsed and continuous-wave Doppler study used to determine the pressure gradient. Balloon angioplasty was considered successful when the coarctation diameter was significantly increased and the post dilatation pressure gradient was $\leq 20 \mathrm{mmHg}$ measured by cuff sphygmomanometer, echocardiographic Doppler-derived peak pressure gradient or at repeat cardiac catheterization if needed, without formation of a significant aneurysm.

An aneurysm was defined as a saccular outpouching protrusion of the aortic wall or fusiform dilatation with a ratio of its diameter to the descending aorta diameter more than 1.5 folds [15].

\section{Statistical analysis}

The data was collected, coded and entered to a personal computer. It was analyzed with the program Excel 2016. Values are expressed as (mean \pm standard deviation). The student paired t-test was used to compare pre- and post angioplasty pressure gradients. A p value less than 0.05 was considered significant.

\section{Results}

In this study the commonest associated lesion found was bicuspid aortic valve with no significant pressure gradient in 8 patients (20\%), followed by aortic valve stenosis in 7 patients $(17.5 \%)$ with no significant pressure gradient. Regarding history and clinical examination all patients were hypertensive for age, but only 14 patients (35\%) were on anti-hypertensive and / or anti-failure treatment. Headache (7\%), shortness of breath (14\%), and difficulty of feeding especially for infants and young children was observed in 12 patients (30\%). In all patients, the pulse in the upper limbs were felt while it was weak and delayed in the lower limbs. The systolic and diastolic blood pressure in the upper limbs ranged from 190 to $120(152.8 \pm 14.2)$ and from 120 to $60(90.1 \pm 13)$ respectively. The systolic and diastolic blood pressure in the lower limbs ranged from 120 to 70 (96.6 \pm 12.4$)$ and from 100 to $50(72.4 \pm 14.9)$ respectively. All patients had an arm to leg-cuff measured systolic pressure gradient $\geq 20 \mathrm{mmHg}$. The electrocardiogram showed left ventricular hypertrophy in 15 patients almost with strain pattern (37.5\%).

A. Doppler echocardiography data before angioplasty: LVEDD ranged from 2.2 to $5.1 \mathrm{~cm}(3.42 \pm 0.51)$, LVESD ranged from 1.4 to $4 \mathrm{~cm}(2.33 \pm 0.52)$. SWT ranged from 0.5 to 1.2 $(0.74 \pm 0.16)$ and the PWT ranged from 0.5 to $1(0.7 \pm 0.12)$. The fractional shortening (FS) ranged from $11 \%$ to $48 \%$ $(33.3 \pm 8.41)$; and the ejection fraction (EF) ranged from $28 \%$

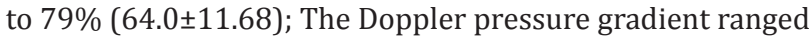
from 30 to $100 \mathrm{mmHg}(57 \pm 15.7)$. Left ventricular concentric hypertrophy was present in 23 patients (57.5\%).

B. Cardiac Catheterization hemodynamic and angiographic data before angioplasty: The measured PG across the coarcted segment ranged from 25 to $85 \mathrm{mmHg}$ $(51.97 \pm 15.24)$. The systolic and diastolic ascending aortic blood pressures were 125 to $195 \mathrm{mmHg}(157.1 \pm 17.97)$ and 55 to $125 \mathrm{mmHg}(92.75 \pm 16.60)$, respectively. The systolic and diastolic descending aortic pressures were 70 to 140 $\mathrm{mmHg}(103.75 \pm 16.16)$ and 40 to $85 \mathrm{mmHg}(74.625 \pm 15.91)$ respectively (Table 1 ).

The transverse aortic arch ranged from 0.82 to 1.3 $\mathrm{cm}(1.06 \pm 0.15)$, the isthmus ranged from 0.63 to $1.3 \mathrm{~cm}$ $(0.91 \pm 0.18)$,the coarcted segment diameter ranged from 0.2 to $0.75 \mathrm{~cm}(4.39 \pm 1.6)$, The descending aortic diameter ranged from 0.7 to $1.5 \mathrm{~cm}(1.14 \pm 0.19)$ (Figure 1$)$. 
Table 1: Comparison between cardiac catheterization hemodynamic data before and immediately after balloon angioplasty.

\begin{tabular}{|c|c|c|c|}
\hline & $\begin{array}{c}\text { Before Angioplasty } \\
\text { Mean } \pm \text { SD }\end{array}$ & $\begin{array}{c}\text { Immediately after Angioplasty } \\
\text { Mean } \pm \text { SD }\end{array}$ & $\begin{array}{c}\text { T test } \\
\text { P }\end{array}$ \\
\hline PG (mmHg) & $51.97 \pm 15.24$ & $9.075 \pm 8.71$ & $<0.001$ \\
\hline AASP (mmHg) & $157.1 \pm 17.97$ & $129.03 \pm 11.99$ & $<0.001$ \\
\hline AADP (mmHg) & $92.75 \pm 16.60$ & $85.2 \pm 10.24$ & $<0.001$ \\
\hline DASP (mmHg) & $103.75 \pm 16.16$ & $119.65 \pm 10.23$ & $<0.001$ \\
\hline DADP (mmHg) & $74.625 \pm 15.91$ & $81.2 \pm 9.36$ & $<0.001$ \\
\hline
\end{tabular}

PG: Pressure Gradient; AASP: Ascending Aorta Systolic Pressure; AADP: Ascending Aorta Diastolic Pressure; DASP: Descending Aorta Systolic Pressure; DADP: Descending Aorta Diastolic Pressure

C. Immediate hemodynamic results: The peak to peak systolic gradient significantly decreased from $51.97 \pm 15.24$ to $9.075 \pm 8.71 \mathrm{mmHg}(\mathrm{P}<0.001)$ with $82.7 \%$ reduction. The systolic ascending aortic pressure significantly decreased from $157.1 \pm 17.97$ to $129.03 \pm 11.99 \mathrm{mmHg} \quad(\mathrm{P}<0.001)$ and the systolic descending aortic pressure significantly increased from $103.75 \pm 16.16$ to $119.65 \pm 10.23 \mathrm{mmHg}$ $(\mathrm{P}<0.001)$. Thirty-seven angioplasty procedures were considered to be immediately successful in $92.5 \%$ of patients. Three patients (7.5\%) had suboptimal immediate results with their recorded pressure gradient 25, 30,40 mmHg. All but 3 patients were discharged 24 hours after balloon angioplasty.

D. Immediate angiographic results: The mean diameter of the coarcted segment doubled significantly from $0.439 \pm 0.16$ to $0.87 \pm 0.16 \mathrm{~cm}(\mathrm{P}<0.001)$; and the isthmic diameter also significantly increased from $0.91 \pm 0.18$ to $0.96 \pm 0.18 \mathrm{~cm}$ $(\mathrm{P}<0.001)$ (Table 2$)$. Immediately after balloon angioplasty a small aneurysm appear in 2 patients the diameter of both didn't exceed double diameter of the descending aorta.

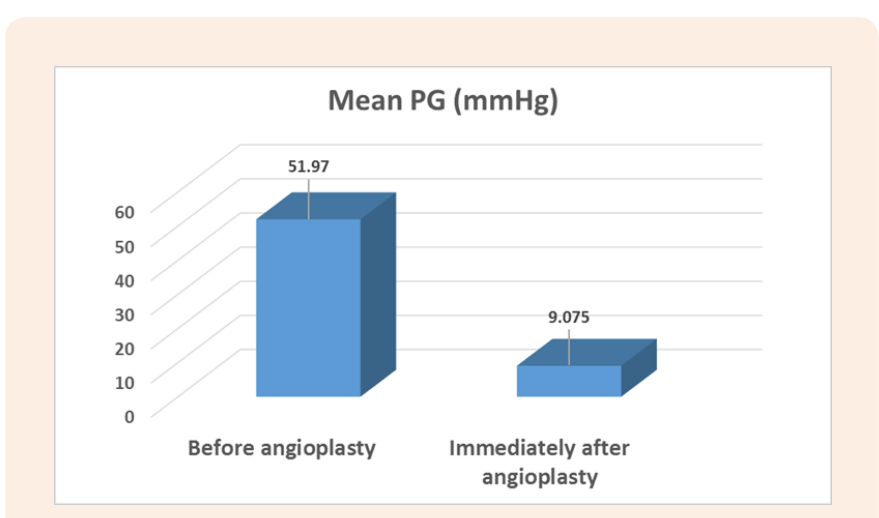

Figure 1: Comparison between pressure gradient across coarcted segment before and immediately after balloon angioplasty.

Table 2: Comparison between cardiac catheterization angiographic data before and immediately after balloon angioplasty.

\begin{tabular}{|c|c|c|c|}
\hline & $\begin{array}{c}\text { Before Angioplasty } \\
\text { (Mean } \pm \text { SD) }\end{array}$ & $\begin{array}{c}\text { Immediately after Angioplasty } \\
\text { (Mean } \pm \text { SD) }\end{array}$ & $\begin{array}{c}\text { T test } \\
\text { P }\end{array}$ \\
\hline TA Diameter $(\mathrm{cm})$ & $1.06 \pm 0.15$ & $1.08 \pm 0.16$ & 0.168 \\
\hline Isth Diameter $(\mathrm{cm})$ & $0.91 \pm 0.18$ & $0.96 \pm 0.18$ & 0.0008 \\
\hline CoA seg Diameter $(\mathrm{cm})$ & $0.44 \pm 1.6$ & $0.87 \pm 1.63$ & 0.0007 \\
\hline DA Diameter $(\mathrm{cm})$ & $1.14 \pm 0.19$ & $1.12 \pm 0.21$ & 0.241 \\
\hline
\end{tabular}

TA: Transverse Arch; Isth: isthmus; CoA seg.: Coarctation Segment; DA: Descending Aorta

\section{Follow up}

9 to 12 months after balloon angioplasty; clinically almost all symptoms were resolved; only 2 patients (5\%) still suffer of shortness of breath; while no patient suffer of that symptom at the 18 to 24 months (Table 3). Mean systolic blood pressure in the upper limb decreased from $(152.8 \pm 14.2)$ to $(129.13 \pm 14.84)$ at the end of the $1^{\text {st }}$ follow-up period and to $(124.25 \pm 15.38)$ at the end of the $2^{\text {nd }}$ follow-up period. Mean systolic blood pressure in the lower limb increased from $(96.6 \pm 12.4)$ to $(117.38 \pm 11.6)$ at the end of the $1^{\text {st }}$ follow-up period and to $(112.25 \pm 12.81)$ at the end of the $2^{\text {nd }}$ follow-up period (Table $4 \& 5$ ).
Follow-up by echocardiography showed decrease in PG from $(57 \pm 15.7)$ at the start of the study to $(14.23 \pm 11.3)$ at the end of the $1^{\text {st }}$ follow-up period and to $(15.15 \pm 11.8)$ at the end of the $2^{\text {nd }}$ follow-up period.

Echocardiography also showed increase in coarctation diameter from $(04.2 \pm 1.7 \mathrm{~mm})$ at the start of the study to $(7.98 \pm 2.35$ $\mathrm{mm})$ at the end of the $1^{\text {st }}$ follow-up period and to $(8.7 \pm 2.27 \mathrm{~mm})$ at the end of the $2^{\text {nd }}$ follow-up period (Table $6 \& 7$ ). At the end of the 1st follow-up period the Recoarctation incidence reached $17.5 \%$ (7 patients) and at the end of the $2^{\text {nd }}$ follow-up period 4 patients (10\%) showed evidence of Recoarctation. 
Table 3: Symptoms at follow up in comparison to pre-angioplasty status.

\begin{tabular}{|c|c|c|c|}
\hline Symptoms & Pre-angioplasty & $\begin{array}{l}9 \text { to } 12 \text { Months } \\
\text { follow-up }\end{array}$ & $\begin{array}{l}18 \text { to } 24 \text { Months } \\
\text { follow-up }\end{array}$ \\
\hline Difficulty in Feeding & $\begin{array}{l}12 \text { patients } \\
(30 \%)\end{array}$ & $\begin{array}{c}0 \text { patients } \\
(0 \%)\end{array}$ & $\begin{array}{c}0 \text { patients } \\
(0 \%)\end{array}$ \\
\hline Intermittent Claudication & $\begin{array}{c}0 \text { patients } \\
(0 \%)\end{array}$ & $\begin{array}{c}0 \text { patients } \\
(0 \%)\end{array}$ & $\begin{array}{c}0 \text { patients } \\
(0 \%)\end{array}$ \\
\hline Shortness of Breath & $\begin{array}{l}16 \text { patients } \\
(40 \%)\end{array}$ & $\begin{array}{l}2 \text { patients } \\
(50 \%)\end{array}$ & $\begin{array}{c}0 \text { patients } \\
(0 \%)\end{array}$ \\
\hline Hypertension & $\begin{array}{l}40 \text { patients } \\
(100 \%)\end{array}$ & $\begin{array}{l}12 \text { patients } \\
(30 \%)\end{array}$ & $\begin{array}{c}3 \text { patients } \\
(7.50 \%)\end{array}$ \\
\hline Headache & $\begin{array}{l}7 \text { patients } \\
(17.50 \%)\end{array}$ & $\begin{array}{c}0 \text { patients } \\
(0 \%)\end{array}$ & $\begin{array}{c}0 \text { patients } \\
(0 \%)\end{array}$ \\
\hline Chest Pain & $\begin{array}{c}0 \text { patients } \\
(0 \%)\end{array}$ & $\begin{array}{c}0 \text { patients } \\
(0 \%)\end{array}$ & $\begin{array}{c}0 \text { patients } \\
(0 \%)\end{array}$ \\
\hline
\end{tabular}

Table 4: Comparison between blood pressure measurement before angioplasty and 9 to 12 months after the procedure.

\begin{tabular}{|c|c|c|c|}
\hline & $\begin{array}{c}\text { Before Balloon } \\
\text { (Mean } \pm \text { SD) }\end{array}$ & $\begin{array}{c}\text { 9 to 12 Months after Balloon } \\
\text { (Mean } \pm \text { SD) }\end{array}$ & $\begin{array}{c}\text { T test } \\
\text { P }\end{array}$ \\
\hline ULSBP & $152.8 \pm 14.2$ & $129.13 \pm 14.84$ & $<0.001$ \\
\hline ULDBP & $90.1 \pm 13$ & $83.5 \pm 10.51$ & 0.003 \\
\hline LLSBP & $96.6 \pm 12.4$ & $117.38 \pm 11.60$ & $<0.001$ \\
\hline LLDBP & $72.4 \pm 14.9$ & $80.25 \pm 10.91$ & 0.006 \\
\hline
\end{tabular}

ULSBP: Upper Limb Systolic Pressure; ULDBP: Upper Limb Diastolic Pressure; LLSBP Lower Limb Systolic Pressure; LLDBP: Lower Limb Diastolic Pressure.

Table 5: Comparison between blood pressure measurement before angioplasty and 18 to 24 months after the procedure.

\begin{tabular}{|c|c|c|c|}
\hline & $\begin{array}{c}\text { Before Balloon } \\
\text { (Mean } \pm \text { SD) }\end{array}$ & $\begin{array}{c}\text { 18 to 24 Months after Balloon } \\
\text { (Mean } \pm \text { SD) }\end{array}$ & $\begin{array}{c}\text { T test } \\
\text { P }\end{array}$ \\
\hline ULSBP & $152.8 \pm 14.2$ & $124.25 \pm 15.38$ & $<0.001$ \\
\hline ULDBP & $90.1 \pm 13$ & $81.75 \pm 10.53$ & $<0.003$ \\
\hline LLSBP & $96.6 \pm 12.4$ & $112.25 \pm 12.81$ & 0.26 \\
\hline LLDBP & $72.4 \pm 14.9$ & $77.13 \pm 6.59$ & 0.006 \\
\hline
\end{tabular}

ULSBP: Upper Limb Systolic Pressure; ULDBP: Upper Limb Diastolic Pressure; LLSBP: Lower Limb Systolic Pressure; LLDBP: Lower Limb Diastolic Pressure.

\section{Medical treatment}

In this study, 86\% (12/14) patients who were taking antifailure and/or antihypertensive medication (as angiotensin converting enzyme inhibitors-ACE, beta blockers and diuretics) could stop them with amelioration of symptoms at the end the $2^{\text {nd }}$ year of follow up.

\section{Doppler Echocardiography}

Table $6 \& 7$ and Figure $2 \& 3$.

Complication: There was no patient mortality related to the procedure within about 24 months following balloon angioplasty. Three patients (7.5\%) which had reduced pulses in the catheterized leg improved later. Blood loss requiring blood transfusion occurred in another three. Early Failure: Three patients showed suboptimal initial procedure with a maximum systolic pressure gradient of more than $20 \mathrm{mmHg}$. Re-catheterization and dilation was done; which was successful in two patients. Aneurysm formation: Two patients (5\%) had small aneurysms at the site of coarctation diagnosed by angiography immediately after balloon angioplasty. Recoarctation: The recoarctation incidence reached $17.5 \%$ in the whole studied population ( $7 / 40$ patients) about the end of the 1st year follow-up. All the patients had successfully repeated angioplasty with post dilatation gradient ranging from 0 to $10 \mathrm{mmHg}$ and 3 of them maintained no clinical evidence of restenosis during their second follow-up period while 4 patients (10\%) developed evidence of restenosis during their second follow-up period. 
Table 6: Comparison between Doppler echocardiographic parameters before balloon angioplasty and 9 to 12 months' follow-up.

\begin{tabular}{|c|c|c|c|}
\hline & $\begin{array}{l}\text { Before Balloon Angioplasty } \\
\text { (Mean } \pm \text { SD) }\end{array}$ & $\begin{array}{l}\text { After } 9 \text { to } 12 \text { Months } \\
\text { (Mean } \pm \text { SD) }\end{array}$ & $\begin{array}{l}\text { T test } \\
\mathbf{P}\end{array}$ \\
\hline LVEDD $(\mathrm{cm})$ & $3.42 \pm 0.51$ & $3.29 \pm 0.29$ & 0.043 \\
\hline $\operatorname{LVESD}(\mathrm{cm})$ & $2.33 \pm 0.52$ & $2.15 \pm 0.3$ & 0.122 \\
\hline FS & $33.3 \pm 8.41$ & $34.86 \pm 4.95$ & 0.285 \\
\hline $\mathrm{EF}$ & $64.0 \pm 11.68$ & $70.56 \pm 4.5$ & 0.091 \\
\hline IVS $(\mathrm{cm})$ & $0.74 \pm 0.16$ & $0.73 \pm 0.121$ & 0.42 \\
\hline $\mathrm{PW}(\mathrm{cm})$ & $0.72 \pm 0.12$ & $0.73 \pm 0.11$ & 0.031 \\
\hline AA diameter $(\mathrm{cm})$ & $1.13 \pm 0.23$ & $11.38 \pm 2.26$ & 0.031 \\
\hline Isth diameter $(\mathrm{cm})$ & $1.01 \pm 0.26$ & $10.5 \pm 2.52$ & 0.0038 \\
\hline CoA seg. diameter $(\mathrm{cm})$ & $0.42 \pm 0.17$ & $7.98 \pm 2.35$ & 0.0041 \\
\hline Doppler PG (mmHg) & $57 \pm 15.7$ & $14.23 \pm 11.30$ & 0.24 \\
\hline
\end{tabular}

LVEDD: Left Ventricular End Systolic Diameter; LVESD: Left Ventricular End Diastolic Diameter; FS: Fraction Shortening; EF: Ejection Fraction; IVS: Interventricular Septum; PW: Posterior Wall; AA: Aortic Arch; Isth: Isthmus; Coa: Coarctation Segment

Table 7: Comparison between Doppler Echocardiographic parameters 9 to 12 months and 18 to 24 months' follow-up after balloon angioplasty.

\begin{tabular}{|c|c|c|c|}
\hline & $\begin{array}{l}\text { After } 9 \text { to } 12 \text { Months } \\
\text { (Mean } \pm \text { SD) }\end{array}$ & $\begin{array}{l}\text { After } 18 \text { to } 24 \text { Months } \\
\text { (Mean } \pm \text { SD) }\end{array}$ & $\begin{array}{c}\text { T test } \\
\mathbf{P}\end{array}$ \\
\hline $\operatorname{LVEDD}(\mathrm{cm})$ & $3.29 \pm 0.29$ & $3.83 \pm 0.44$ & 0.056 \\
\hline LVESD $(\mathrm{cm})$ & $2.15 \pm 0.3$ & $2.22 \pm 0.29$ & 0.024 \\
\hline FS & $34.86 \pm 4.95$ & $35.62 \pm 5.17$ & 0.14 \\
\hline $\mathrm{EF}$ & $70.56 \pm 4.5$ & $70.3 \pm 3.85$ & 0.34 \\
\hline $\operatorname{IVS}(\mathrm{cm})$ & $0.73 \pm 0.121$ & $0.75 \pm 0.12$ & 0.29 \\
\hline $\mathrm{PW}(\mathrm{cm})$ & $0.73 \pm 0.11$ & $0.73 \pm 0.11$ & 0.42 \\
\hline AA diameter $(\mathrm{mm})$ & $11.38 \pm 2.26$ & $11.68 \pm 1.85$ & 0.03 \\
\hline Isth diameter (mm) & $10.5 \pm 2.52$ & $10.9 \pm 2.12$ & 0.003 \\
\hline CoA seg. diameter (mm) & $7.98 \pm 2.35$ & $8.7 \pm 2.27$ & 0.004 \\
\hline Doppler PG (mmHg) & $14.23 \pm 11.30$ & $15.15 \pm 11.80$ & 0.24 \\
\hline
\end{tabular}

LVEDD: Left Ventricular End Systolic Diameter; LVESD: Left Ventricular End Diastolic Diameter; FS: Fraction Shortening; EF: Ejection Fraction; IVS: Interventricular Septum; PW: Posterior Wall; AA: Aortic Arch; Isth: Isthmus; CoA: Coarctation Segment

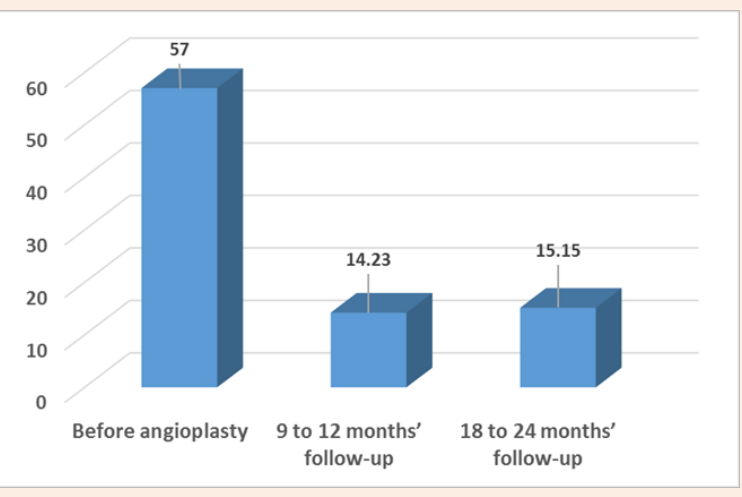

Figure 2: Comparison between pressure gradient across the coarcted segment diameters before angioplasty, 9 to 12 months and 18 to 24 months follow up periods.

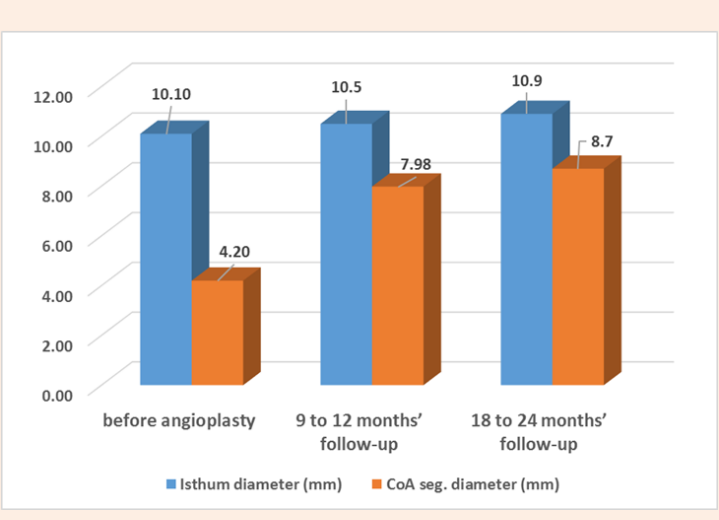

Figure 3: Comparison between isthmus and coarcted segment diameters before angioplasty, 9 to 12 months and 18 to 24 months follow up periods. 


\section{Discussion}

A. Immediate results: Immediate successful relief of native coarctation was obtained in $92.5 \%$ of our population study. While $7.5 \%$ of the patients recorded immediate suboptimal results with PG above $20 \mathrm{mmHg}$. By the end of the study, $87.5 \%$ of our patient population have PG less than $20 \mathrm{mmHg}$ across the coarcted segment (35 patients); $10 \%$ show evidence of recoarctation (4 patients) while the procedure failed in 1 patient. The peak systolic gradient across the coarcted segment was reduced significantly with $82.5 \%$ reduction in pressure gradient immediately after balloon angioplasty measured in cath lab, $75 \%$ and $73.2 \%$ at the end of $1^{\text {st }}$ and $2^{\text {nd }}$ follow up period respectively recorded by echocardiography and, as a result of the procedure, the systolic ascending aortic pressure decreased significantly (19\%) and the systolic descending aortic pressure increased significantly $(11.4 \%)$ at the end of the study.

B. Intermediate results about two-years follow-up: The late results of balloon angioplasty are considered good when residual pressure gradient was reduced to $\leq 20 \mathrm{mmHg}$ measured by cuff sphygmomanometer, Doppler-derived peak instantaneous PG, cardiac catheterization as well as the absence of restenosis and no significant aortic aneurysm on follow-up [16].

The Doppler measured pressure gradient decreased significantly from (mean \pm SD) $57 \pm 15.7 \mathrm{mmHg}$ before balloon angioplasty to $14.23 \pm 11.30 \mathrm{mmHg}(\mathrm{p}=0.003)$ after 9 to 12 months but it increased slightly to reach $15.15 \pm 11.80 \mathrm{mmHg}(\mathrm{p}=0.002)$ at the end of the second year of follow up. This is similar to reports published by other researchers. Lan He et al. [17], reported that the systolic peak pressure gradient (PG) across the coarctation was $41.0 \pm 16.0 \mathrm{mmHg}$ (range $13-76 \mathrm{mmHg}$ ) which was significantly decreased to $13.0 \pm 11.0 \mathrm{mmHg}$ (range $0-40 \mathrm{mmHg}$ ) and Massoud et al. [15], reported that peak-to-peak systolic gradient decreased from $55.65 \pm 15$ to $9.6 \pm 8 \mathrm{mmHg}(\mathrm{p}<0.0001)$ [15].

\section{Recoarctation}

In this study recoarctation incidence reached $17.5 \%$ in the whole studied population (7/40 patients) about the end of the $1^{\text {st }}$ year follow-up, but it was up to $25 \%$ among infants aged one year or less ( $2 / 8$ patients). All the 7 children ( 6 of them were male children) had successful repeat angioplasty with post dilatation gradient ranging from 0 to $10 \mathrm{mmHg}$ and 3 of them maintained no clinical evidence of restenosis during their second follow-up period while 4 patients (10\%) showed evidence of restenosis during their second follow-up period.

The relatively lower recoarctation rate met in our study could be explained by the low percentage of infant age group (one year or less) as they consist $20 \%$ only of the studied population (8/40 children). In other studies, when series include neonates and infants, the incidence of recoarctation is higher. The population in the Rao et al. [18] study, ranged from 2 days to 15 years. At a mean follow up period of $14 \pm 11$ months. They showed $25 \%$ recoarctation rate. (83\% in neonates less than 30 days old, $39 \%$ in infants less than 1 year old, $8 \%$ in children). Several risk factors exist for recoarctation after balloon angioplasty, including age at initial repair $<2-3$ months, weight at initial repair $<5 \mathrm{~kg}$, size of aortic isthmus (isthmic hypoplasia), small coarcted segment diameter [19].

\section{Aneurysm formation}

In the present study, aneurysm at the site of coarctation developed in 2 patients (5\%) diagnosed by angiography immediately after balloon angioplasty. This was comparable to Massoud et al. [15], who reported in their study that the incidence of immediate aneurysm formation was $6.5 \%$. The pathological basis for aneurysm formation may be similar to the mechanism by which balloon angioplasty relieves coarctation, namely controlled tearing of aortic intima and media. Other additive factors may contribute to the formation of aneurysm at the site of balloon dilatation such as, the use of larger balloons or inherited wall abnormalities (cystic medial necrosis). This is found in the form of severe depletion and disarray of elastic tissue. It is not clear, whether those factors could act independently or in contribution to produce such aneurysm [20].

In our study the total number of patients suffering from complications is 8 out of 40 patients (20\%).No one suffered from life threatening incidents or major complications related to the procedure or requiring immediate surgical intervention. Three patients $(7.5 \%)$ suffered from blood loss during angioplasty requiring blood transfusion. Three patients (7.5\%) suffered from peripheral vascular complications and were treated by IV low molecular weight heparin and were discharged at the same week. Two patients (5\%) suffered from in situ aneurysm formation and one patient $(2.5 \%)$ suffered from suboptimal results in spite of 3 repeated angioplasty procedures throughout the study duration.

\section{Medical treatment}

The treatment of hypertension in coarctation of the aorta is ideally managed by early surgical or trans catheter repair to reduce the risk of irreversible aortopathy and refractory hypertension, in addition to other associated squeals including premature coronary artery disease; stroke; aortic aneurysm, dissection, and rupture; infective endocarditis; and heart failure. In a large follow up study including 646 patients with aortic coarctation, it was found that hypertension occurred in $7 \%$ of patients operated on as infants, as opposed to $33 \%$ of patients who had repair performed after the age of 14 years; The study also found age at the time of initial repair to be the most important predictor of hypertension [21]. In our study, 85.7\% (12/14) patients who were taking both anti-failure and antihypertensive medication could stop them with amelioration of symptoms at the end the $2^{\text {nd }}$ year of follow up. By the end of the study $95 \%$ (38/40) of patients were not taking any medical treatment and the patients who were still on antihypertensive and anti-failure medications were referred to surgery.

Massoud et al. [15] reported that almost all the children studied stopped medication by the end of 24-60month follow up period except for three who were also referred to surgery due to aneurysms. Another 4 patients (all children) had a cuff pressure gradient of 20-22 mmHg with hypertension, without angiographic evidence of restenosis associated with persistent mild isthmus hypoplasia; they received atenolol and captopril [15]. 


\section{Conclusion}

Percutaneous balloon angioplasty was still found to represent an effective and successful mean of relieving obstruction due to native discrete aortic coarctation in infants older than 2 months and children 10 years of age or less.

\section{Conflict of interest}

No relationship.

\section{References}

1. Doshi AR, Syamasundar Rao P (2012) Coarctation of AortaManagement Options and Decision Making. Pediat Therapeut S5: 006.

2. Myers JL, McConnell BA, Waldhausen JA (1992) Coarctation of the aorta in infants: does the aortic arch grow after repair? Ann Thorac Surg 54(5): 869-874.

3. Schranz D, Zartner P, Michel-Behnke I, Akinturk H (2006) Bioabsorbable metal stents for percutaneous treatment of critical recoarctation of the aorta in a newborn. Catheter Cardiovasc Intern 67(5): 671-673.

4. Lock JE, Bass JL, Amplatz K, Fuhrman B, Castaneda-Zuniga WR (1983) Balloon dilation angioplasty of aortic coarctation in infants and children. Circulation 68(1): 109-116.

5. Lababidi Z, Daskalopoulos DA, Stoecle H Jr (1984) Transluminal balloon angioplasty: experience with 27 patients. Am J Cardiol 54(10): 1288-1291.

6. Rao PS, Thapar MK, Kutaily F, Carey P (1989) Causes of recoarctation after balloon angioplasty of unoperated aortic coarctation. J Am Coll Cardiol 13(1): 109-105.

7. Rao PS, Thapar MK, Galal O, Wilson AD (1990) Follow-up results of balloon angioplasty of native coarctation in neonates and infants. Am Heart J 120(6 Pt 1): 1310-1314.

8. Tynan M, Finley JP, Fontes V, Hess J, Kan J (1990) Balloon angioplasty for the treatment of native coarctation: results of valvuloplasty and angioplasty of congenital anomalies registry. Am J Cardiol 65(11): 790-792.

9. Walhout RJ, Lekkerkerker JC, Ernst SM, HutterPA, Plokker TH, et al. (2002) Angioplasty for coarctation in different aged patients. Am Heart J 144(1): 180-186.
10. Fawzy ME, Awad M, Hassan W, Al Kadhi Y, Shoukri M, et al. (2003) Long-term outcome (up to 15 years) of balloon angioplasty of discrete native coarctation of the aorta in adolescents and adults. J Am Cardiol 43(6): 1062-1067.

11. Kodolitsch Y, Aydin MA, Koschyk DH, Loose R, Schalwat I, et al. (2002) Predictors of aneurismal formation after surgical correction of aortic coarctation. J Am Coll Cardiol 39(4): 617-624.

12. Jeffery M, Matthew M, Doff B Mc, Kerry Mc, Richard R (2015) Investigators Intermediate Outcomes in the Prospective, Multicenter Coarctation of the Aorta Stent Trial (COAST). Circulation 131: 16561664.

13. Catherine M Otto (2012) The Practice of Clinical Echocardiography. ( $4^{\text {th }}$ edn), Elsevier Saunders publication, USA.

14. Horst S, Shakeel A Q Neil W, Ziyad M H (2015) Interventions in Structural, Valvular, and Congenital Heart Disease. ( $\left.2^{\text {nd }} e d n\right), C R C$ Press.

15. Massoud Iel S, Farghly HE, Abdul-Monem A, Botros N, Kassem A, et al. (2008) Balloon angioplasty for native aortic coarctation in different anatomic variants. Pediatr Cardiol 29(3): 521-529.

16. Cowley CG, Orsmond GS, Feola P, McQuillan L, Shaddy RE (2005) Long-term, randomized comparison of balloon angioplasty and surgery for native coarctation of the aorta in childhood. Circulation 111(25): 3453-3456.

17. Lan He, Fang Liu, Lin Wu, Chun-Hua Qi, Li-Feng Zhang, et al. (2015) Percutaneous Balloon Angioplasty for Severe Native Aortic Coarctation in Young Infants Less Than 6 Months: Medium- to Longterm Follow-up 2014. Chin Med J (Engl) 128(8): 1021-1015.

18. Rao PS, Galal O, Smith PA, Wilson AD (1996) Five-to nine-year followup results of balloon angioplasty of native aortic coarctation in infants and children. J Am Coll Cardiol 27(2): 462-470.

19. Kpodonu J, Ramaiah VG, Rodriguez Lopez JA, Diethrich EB (2010) Endovascular management of recurrent adult coarctation of the aorta. Ann Thorac Surg 90(5): 1716-1720.

20. Ovaert C, McCrindle BW, Nykanen D, MacDonald C, Freedom RM, et al. (2000) Balloon angioplasty of native coarctation: clinical outcomes and predictors of success. J Am Coll Cardiol 35(4): 988-996.

21. Cohen M, Fuster V, Steele PM, Driscoll D, McGoon DC (1989) Coarctation of the aorta. Long-term follow-up and prediction of outcome after surgical correction. Circulation 80(4): 840-845. 